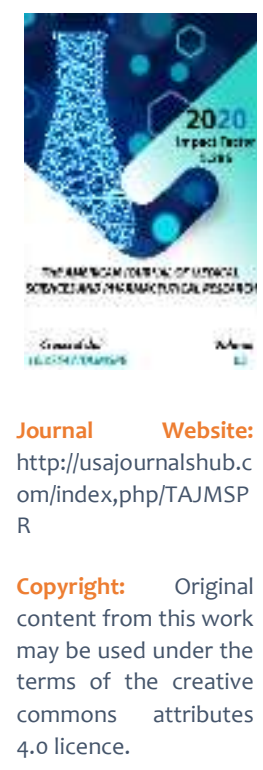

\title{
Caries And Dental Diseases In Children
}

Rahimberdiyev Rustam Abdunosirovich

Samarkand State Medical Institute Head Of The Department Of Pediatric Dentistry, Samarkand Region, Uzbekistan

Abdikodirova Baxora Maxmadiyor Qizi

Samarkand State Medical Institute Clinical Resident Of The Department Of Pediatric

Dentistry, Samarkand Region, Uzbekistan

Mavlonova Dilorom Oybek Qizi

Samarkand State Medical Institute Clinical Resident Of The Department Of Pediatric Dentistry, Samarkand Region, Uzbekistan

\section{ABSTRACT}

This article has been reported mainly for the Prevention of caries and dental diseases in children. The article mentioned the causes of the origin of the common disease and the first AIDS. In addition, the article mentioned the stages of development of dental diseases.

\section{KEYWORDS}

Diseases, caries, milk teeth, oral and dental hygiene, calcium fluoride, dental disease

\section{INTRODUCTION}

Caries can appear not only in adults, but also in children, and even in milk teeth. The reasons for the appearance of a career plaque in children:

1. Insufficient oral and dental hygiene.
2. Excessive consumption of sweets and foods containing a large amount of carbohydrates.

3. Ifikifigators and nipple bottles have been used for a long time.

4. With food, the child receives little useful elements (fluorine). 
The decay of deciduous teeth, despite the fact that they fall out, should be treated. The fact is that if the milk teeth are not treated, the bacteria remain in the oral cavity and continue to damage the tooth tissue, thereby complicating the process of eruption of permanent teeth.

\section{MATERIALS AND METHODS}

The development of dental diseases is carried out in three stages.

1-stage - the beginning. At this stage, it is very difficult to diagnose caries without seeing a dentist, because in the tooth enamel appears a plaque that is barely visible, which does not cause any discomfort and pain.

2-stage - average. At this stage, the place with the stain is already significantly enlarged and painful sensations appear, especially under the influence of "irritant" (hot, cold, contact with the toothbrush).

3-stage - deep caries. It is characterized by damage to the enamel and tooth root. Periodontitis, pulpitis, inflammatory processes begin.

Self-treatment of caries is accepted in the first two stages. Deep caries cannot be treated at home, and self-treatment only furthers the situation. Also, with a complicated form of the disease, you need to go to the dentist as soon as possible.

Treatment of caries in the initial and middle stages at home is a rather long and difficult process, which requires a lot of time and effort. Do not expect an urgent result, because the restoration of tooth enamel occurs gradually.

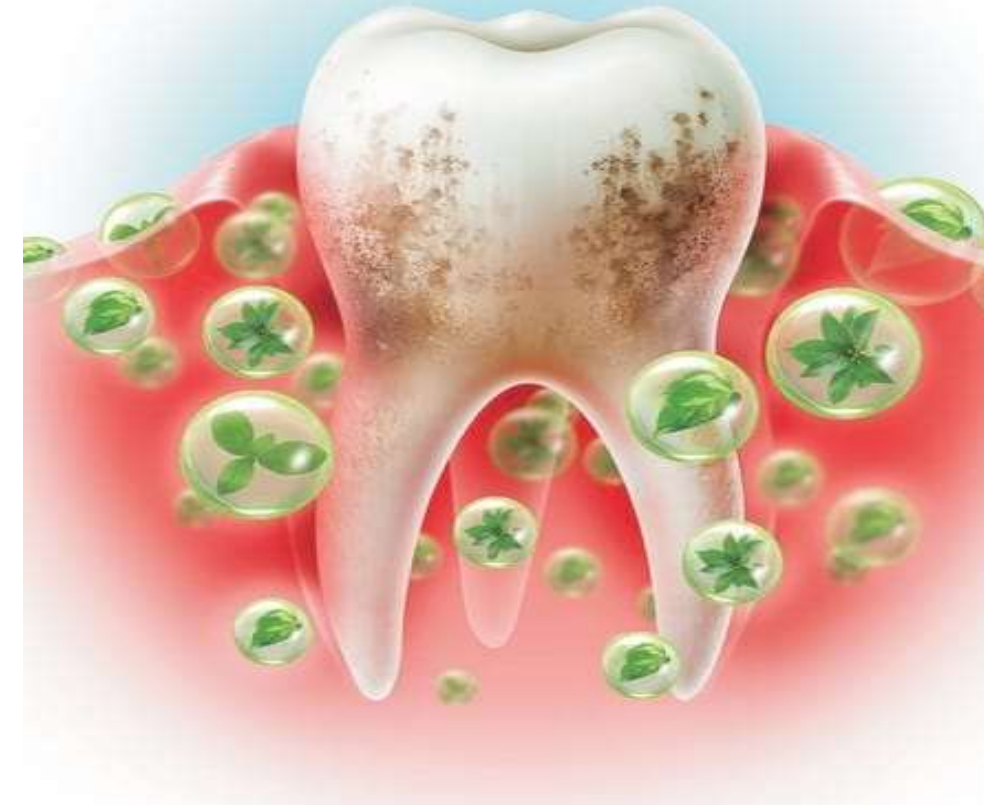

figure 1

Alternative methods of treating caries are aimed at destroying bacteria and reducing inflammation. Rinses and compresses are the most effective way to combat caries plaque.

1. Propose fights bacteria and enriches tooth enamel with minerals and destroys the microorganism of the crown. To prepare a rinse, you will need 2 tablespoons. Dilute proposes in $250 \mathrm{ml}$ of boiled water. Wash for at least two minutes.

2. Sage very effectively affects microbes and destroys them. For the procedure, you will need 2 tablespoons. Pour the sage into a glass of boiling water. Boil for an hour.

3. Tirade calms air toothache. To make a solution, you need to finely chop the roots of parsley and pour a liter of vodka. Allow to ripen for a week. After washing your teeth with this solution, you need to rinse your mouth at night. 
4. Everyone knows that laundry soap copes well with fungi and bacteria. Water-soap solution will help to get rid of tooth decay from dental diseases.

5. Onion husks not only kill bacteria, but also reduce pain. 2 tablespoons of onion husks should be poured a liter of boiling water and left for a day to insist. After that, the infusion is filtered. Wash once a day.

6. Camphor oil is used as a compress. It removes pain well, and also helps to restore tissues. It is enough to apply a cotton pad soaked in camphor oil to the affected tooth for a few minutes. Oil can be rubbed into the gum around the sick tooth.

7. Saline helps to keep teeth and gums healthy. To prepare the solution, you will need a sea tizzy or a simple table tizzy. It is necessary to pour 2 tablespoons of salt with a glass of warm, boiled water. The salt in the glass should be mixed until completely dissolved. Such a solution can be used throughout the day after each meal.

8. With inflammation of the gums, infusion of aloe and lemon balm helps well. He will take 1 tablespoon. Chopped aloe leaves, 2 tablespoons. St. John's worth and 8 tablespoons of lemon balm. You need to grind, mix and pour 3 glasses of boiling water. The mixture is infused for four hours.

9. Horsetail helps to destroy bacteria that provoke the development of caries. With a solution of horse meat, you can rinse your mouth after each meal or simply chew 5 times a day for 2-3 minutes.
1. Elizarova V. M., Drobotoko L. N., Strakhova S. Yu. / / Lech. doctor. - 2000. no. 8. - P. 27-29.

2. Isakov V. A., Rybalkin S. B., Romantsov M. $G$. herpesvirus infection: a manual for doctors. - SPb., 2006. - 95 p.

3. Levonchuk E. A. herpetic infection of a polostyrta // Tell lies. dentistry. - 2005. №1. - C.19-23

4. Looker, KJ; Garnett, GP; Schmid, GP (October 2008). "An estimate of the global prevalence and incidence of herpes simplex virus type 2 infection". Bulletin of the World Health Organization. 86 (10): 805-12, A.

5. Dickerson FB, Boronow JJ, Stallings $C$, et al. (March 2004). "Infection with herpes simplex virus type 1 is associated with cognitive deficits in bipolar disorder". Biol. Psychiatry. 55 (6): 588-93.

6. Rapini, Ronald P.; Bolognia, Jean L.; Jorizzo, Joseph L. (2007). Dermatology: 2Volume Set. St. Louis: Mosby. ISBN 978-14160-2999

7. Baratova sh. N., Rakhimberdiev R. A., Shamsiev R. A. "Features of the course and diagnosis of dental caries in children of primary school age". Achievements of science and education-scientific and methodological journal, 2020, no. 1 (55), pp. $83-88$

8. Ubaidullaeva M. A., R. A. Rahimberdiev, Shamsiev.And . "Hygienic care of the oral cavity in children of early age". Achievements of science and educationscientific and methodological journal, 2020, no. 1 (55), pp. 88-94

9. Baratova sh. N., Rakhimberdiev R. A., Shamsiev R. A. "Prevention of permanent dental caries in children of primary school age". Achievements of science and 
The American Journal of Medical Sciences and Pharmaceutical Research

(ISSN - 2689-1026)

Published: November 30, 2020 | Pages: 123-126

IMPACT FACTOR

2020: 5.286

Doi: https://doi.org/10.37547/TAJMSPR/Volumeo2Issue11-22

OCLC - 1121105510

education-scientific and methodological

journal, 2020, no. 4 (58), pp. 67-75

10. Zubaydullayeva M. A., Rakhimberdiev R. A.

"dental Caries in young children:

epidemiology, etiology, prevention, treatment". Achievements of science and education-scientific and methodological journal, 2020, no. 4 (58), pp. 79-88 